\title{
Influence of surface nano/ultrafine structure formed via pre-deep rolling process on the plasma nitriding characteristics of the AISI 316L stainless steel
}

\author{
A. Jafari Tadi ${ }^{1} \cdot$ S. R. Hosseini ${ }^{1} \cdot$ M. Naderi Semiromi ${ }^{1}$
}

Received: 25 January 2017/Accepted: 8 August 2017/Published online: 30 August 2017

(c) The Author(s) 2017. This article is an open access publication

\begin{abstract}
Influence of deep rolling prior to plasma nitriding on microstructure and hardness of the AISI 316L stainless steel was investigated in this paper. Deep rolling using 'ball-point' tool was conducted on the $316 \mathrm{~L}$ stainless steel bar at multiple passes. Then, plasma nitriding was performed on the as-received and deep-rolled kinds at $450{ }^{\circ} \mathrm{C}$ temperature for $5 \mathrm{~h}$. Structural characterisation was done using optical microscope, field emission scanning electron microscope, feritscope, X-ray diffractometer, and glow discharge optical emission spectroscope as well as hardness measurement by a Vickers micro-hardness tester at $0.1 \mathrm{kgf}$. An ultrafine structure and a nitrogen-rich layer were, respectively, formed on the rolled and nitrided surfaces. Surface hardness was increased from 210 up to 450 , 670 and $1050 \mathrm{HV}_{0.1}$ after the rolling, nitriding, and rollingnitriding processes, respectively. Thickness of the nitrided layer was increased from 12 to $20 \mu \mathrm{m}$ and diffusion depth of nitrogen from 12 to $25 \mu \mathrm{m}$ via conducting the deep rolling before the nitriding process. The rolling-nitriding process was resulted in rising of nitrogen concentration by a factor of about 3 at near-surface regions.
\end{abstract}

Keywords Austenitic stainless steel - Deep rolling · Plasma nitriding

A. Jafari Tadi

abdolrezajafari68@gmail.com

1 Department of Materials Engineering, Malek-Ashtar University of Technology, Isfahan 83145-115, Islamic Republic of Iran

\section{Introduction}

Austenitic stainless steels such as the AISI 316L have an excellent corrosion resistance and good formability [1]. These materials need high levels of surface hardness and wear resistance as relatively low hardness and poor wear resistance have resulted in their limited application [2].

Plasma nitriding is a well-known diffusional treatment to solve this problem that improves the mechanical properties of austenitic stainless steels, such as hardness and wear resistance [3-5]. Increase in the thickness and nitrogen concentration of nitrided layer is an important industrial requirement to improve the hardness, wear resistance, and several other properties in austenitic stainless steels. The temperature of $450{ }^{\circ} \mathrm{C}$ is an optimum temperature to obtain a relatively thick nitrided layer with appropriate corrosion resistance in the plasma-nitrided AISI 316L steel [5-7]. But, a thicker nitrided layer is required in several applications and this requirement can be achieved by increasing the diffusion coefficient of nitrogen. Diffusion coefficient of elements is increased with raising the density of crystalline defects [8]. Hence, increasing the density of crystalline defects in the surface regions can result in more diffusivity of nitrogen as well as more hardness and further thickness of nitrided layer in austenitic stainless steels.

Surface mechanical treatments, such as ultrasonic shot peening $[9,10]$, mechanical attrition [11, 12], laser shock peening $[13,14]$, burnishing $[15,16]$, and deep rolling $[17,18]$, are the appropriate methods to increase the density of crystalline defects in the surface regions via a surface severe plastic deformation. By applying these treatments, three effects consisting of "work hardening", "structural alteration", and "residual stress induction" are achieved in surface zones [9, 11, 14, 16, 17]. Therefore, nitrogen diffusivity affected by raised crystalline defects as 
well as surface hardness and wear resistance will be enhanced by these treatments. According to studies, conducting the surface mechanical treatment prior to nitriding can induce a thicker nitrided layer with more hardness as well as further wear resistance in an austenitic stainless steel [7, 18].

Several experimental studies reported so far about the effects of surface mechanical treatments and plasma nitriding on the properties of austenitic stainless steels are as follows: Nikitin et al. [17] and Altenberger et al. [19] produced a surface nanostructure with only $2 \mu \mathrm{m}$ thickness on the AISI 304 stainless steel by deep rolling, which resulted in increased surface hardness from 200 to 360 $\mathrm{HV}_{0.5}$. Hashemi et al. [18] investigated the effect of shot peening on the nitriding behavior of the AISI 316L stainless steel. Due to the surface grain refinement, a thicker nitrided layer with further hardness (increased from 250 up to $700 \mathrm{HV}_{0.1}$ ) was induced at the shot peened-nitrided part, compared with a nitrided one. Lin et al. [7] evaluated the tribological properties of the plasma-nitrided AISI 321 stainless steel and showed that wear resistance of the treated steel has significantly been increased. In addition, applying the surface mechanical attrition treatment before plasma nitriding (combined state) was followed more surface hardness and further wear resistance, compared to the individual treating. Ji et al. [20] studied the effect of a modified layer caused via pre-shot peening and transformation of austenite to martensite on plasma nitriding of the AISI 304 stainless steel at $450{ }^{\circ} \mathrm{C}$. The thickness of nitrided layer in shot peened-nitrided processed type was about $13 \mu \mathrm{m}$, while just $5 \mu \mathrm{m}$ for specimen without predeforming.

In previous works, several mechanical surface treatments such as shot peening and mechanical attrition conducted before plasma nitriding as the duplex process and their effects on the structural characteristics and surface hardness of austenitic stainless steels have been investigated. But, deep rolling in combination of nitriding and their structural changes has not so far been reported. Therefore, in the present work, the effects of deep rolling and plasma nitriding processes at the duplex state on the structural characteristics and surface hardness of an austenitic stainless steel are evaluated. The main aim of this paper was to evaluate the effect of deep rolling on the nitrogen diffusion depth and thickness of nitrided layer. Deep rolling and afterwards plasma nitriding were applied on the AISI 316L stainless steel. Structural characterisation was done by scanning electron microscope (SEM), X-ray diffractometer (XRD), feritscope and, glow discharge optical emission spectroscopy (GDOES). Micro-hardness tester was employed to measure the surface hardness. The results of structural characterisation and hardness tests are compared and discussed at different conditions of the processes.

\section{Experimental}

\section{Materials and processes}

Experiments were carried out on the as-received hot-rolled bar of the AISI 316L stainless steel named UT with $30 \mathrm{~mm}$ diameter, $210 \pm 5 \mathrm{HV}_{0.1}$ average hardness, chemical composition (wt\%): $\mathrm{Fe}-0.03 \quad \mathrm{C}-17.50 \mathrm{Cr}-10.50 \mathrm{Ni}-$ 2.15 Mo-1.81 Mn-0.50 $\mathrm{Si}$ and austenitic structure with $25 \pm 5 \mu \mathrm{m}$ average grain size as shown in Fig. 1. For conducting the deep rolling process, a "ball-point" tool equipped with a tungsten carbide ball with $20 \mathrm{~mm}$ diameter was employed. The process was performed at 15 passes that generated totally $110 \mu \mathrm{m}$ diameter reduction of the deep-rolled bar named DR. During the applied process, "ball-point" tool glided 15 times from right to left (and reversely) on the surface of the steel bar.

Plasma nitriding process was performed at a semi-industrial system composed of a vacuum chamber with $600 \mathrm{~mm}$ internal diameter and $670 \mathrm{~mm}$ height, $7 \mathrm{~kW}$ power supply, $220 \mathrm{~V}$ bias, and water circulation system. Prior to the nitriding, the selected specimens (UT \& DR) were cleaned by acetone solution for $15 \mathrm{~min}$. The nitriding was started by ion sputtering inside "50 $\mathrm{Vol} \% \mathrm{H}_{2}+50$ Vol\% Ar" atmosphere with 0.4 Torr pressure for $60 \mathrm{~min}$ up to $110^{\circ} \mathrm{C}$, and then heating to $450{ }^{\circ} \mathrm{C}$. During the process, temperature was measured using a thermocouple with $1{ }^{\circ} \mathrm{C}$ accuracy. After reaching the mentioned temperature $\left(450{ }^{\circ} \mathrm{C}\right)$, the "75 $\mathrm{Vol} \% \mathrm{H}_{2}+25 \mathrm{Vol} \% \mathrm{~N}_{2}$ " atmosphere with 5 Torr pressure was chosen for the sake of

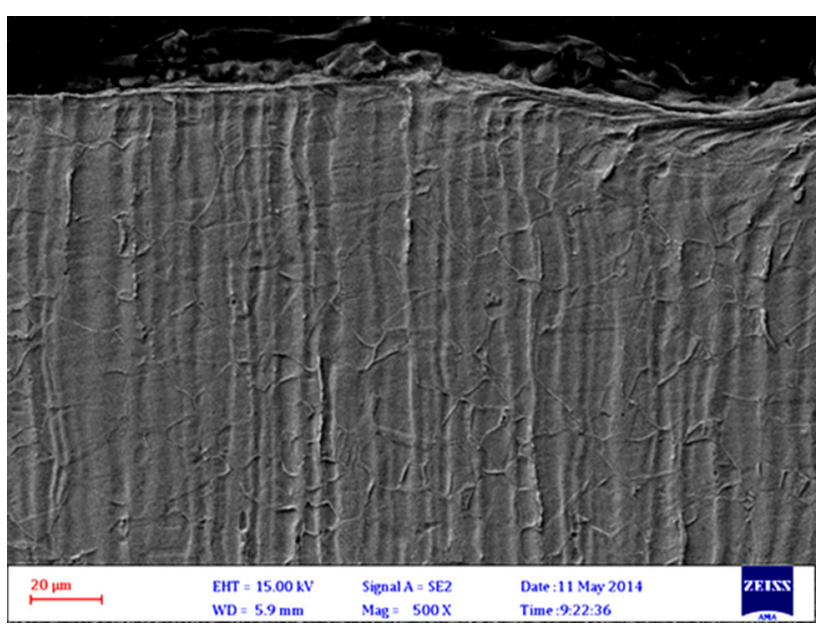

Fig. 1 FESEM micrograph from the near-surface regions prior to treating (UT) 
the desired process. Plasma nitriding at $450{ }^{\circ} \mathrm{C}$ for $5 \mathrm{~h}$ may be resulted in a relatively thick nitrided layer with saved corrosion resistance [5]. Hence, the selected temperature and duration are appropriate parameters and corrosion properties may be conserved, which is the main aim when the AISI 316L is subjected by nitriding. The process was performed on the as-received (UT) and deep rolling processed (DR) kinds, where resulted in the as-received plasma nitrided (UPN) and deep-rolled plasma nitrided (DPN) types, respectively. After the nitriding, the samples were cooled in vacuum conditions and collected at the ambient temperature.

\section{Characterisation of the surface}

Optical (OM, PME3 type), scanning electron (SEM, LEITS type), and field emission scanning electron (FESEM, ZEISS type) microscopes were used to observe the microstructure at the different conditions, determination of affected depth and thickness of diffusion zone as well as average grain size related to the nitriding and deep rolling processed kinds. Employed FESEM was an appropriate instrument for illustration of nano/ultrafine grains. After both the rolling and nitriding processes, cross-section of the samples were wet ground using $\mathrm{SiC}$ grinding papers and then polished for achievement of a mirror-like surface and afterwards etched by " $10 \mathrm{ml} \mathrm{HCL}+10 \mathrm{ml}$ $\mathrm{HNO}_{3}+10 \mathrm{ml}$ acetic acid +2 drops glycerol" etchant.

Phasic characterisation was done using feritscope (Fischer FMP30) and X-ray diffractometer (MPD-X'PERT) conducted using $\mathrm{Cu} \mathrm{K} \mathrm{K}_{\alpha}$ radiation with $1.542515 \AA$ wave length at scanning range from 30 to $100^{\circ}, 0.05^{\circ}$ step size, and scan step time of $1 \mathrm{~s}$. Glow discharge optical emission spectroscopy (GDOES, JOBIN-YVON type) at $850 \mathrm{~Pa}$ pressure, $70 \mathrm{~W}$ source power, and $50 \mathrm{~S}$ vacuum duration was done to obtain the elemental concentration profile from surface into substrate after the nitriding process. Surface hardness was determined using a Vickers micro-hardness tester at $0.1 \mathrm{kgf}$, after five trials per one. Considering the hardness tester, $0.1 \mathrm{kgf}$ was an optimum force for hardness measurement.

\section{Results and discussion}

\section{Microstructure and hardness}

Figure 2 shows FESEM micrograph indicating the crosssectional morphology of near-surface regions after the DR process. As can be seen in Fig. 2a, ultrafine grains $(G)$ have been formed inside structure. According to Fig. 2b, grainrefined layer has an extending depth in about $60 \mu \mathrm{m}$. Due to the texture effect in grain refinement, ultrafine grains

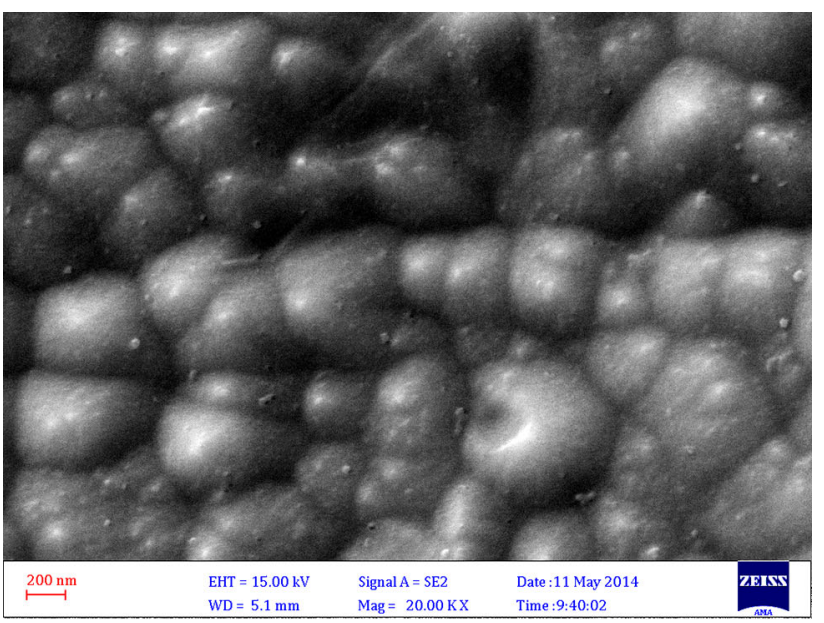

(a)

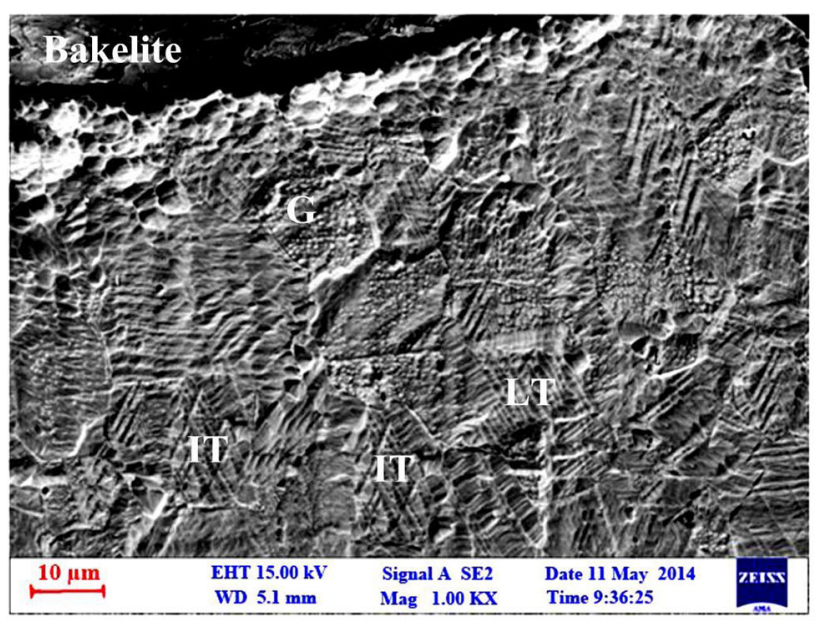

(b)

Fig. 2 FESEM micrograph from the near-surface regions after the deep rolling $(\mathrm{DR})$ process

(G) have been formed inside some micro-sized grains. In addition, formation of deformation bands identified as mechanical twins in such austenitic stainless steel [21] is observed in this figure. Therefore, the deep rolling has been resulted in the formation of ultrafine grains $(G)$ intersecting (IT) and lamellar (LT) mechanical twins. Severe plastic deformation during the rolling of such austenitic stainless steel has been shown to be responsible for the structural refinement and nanocrystallization in the near-surface regions [11, 17, 21-23].

Moreover, the severe plastic deformation and surface grain refinement; formation of strain-induced martensite is another structural change in austenitic stainless steels $[11,21]$. According to Fig. 3, the XRD pattern of nearsurface regions after the deep rolling process has been composed of retained austenite $(\gamma)$ and strain-induced martensite $\left(\alpha^{\prime}\right)$. The (110), (200), (211), and (220) peaks of $\alpha^{\prime}$ martensite have been formed after the deep rolling process. The severe plastic deformation is often led to the 


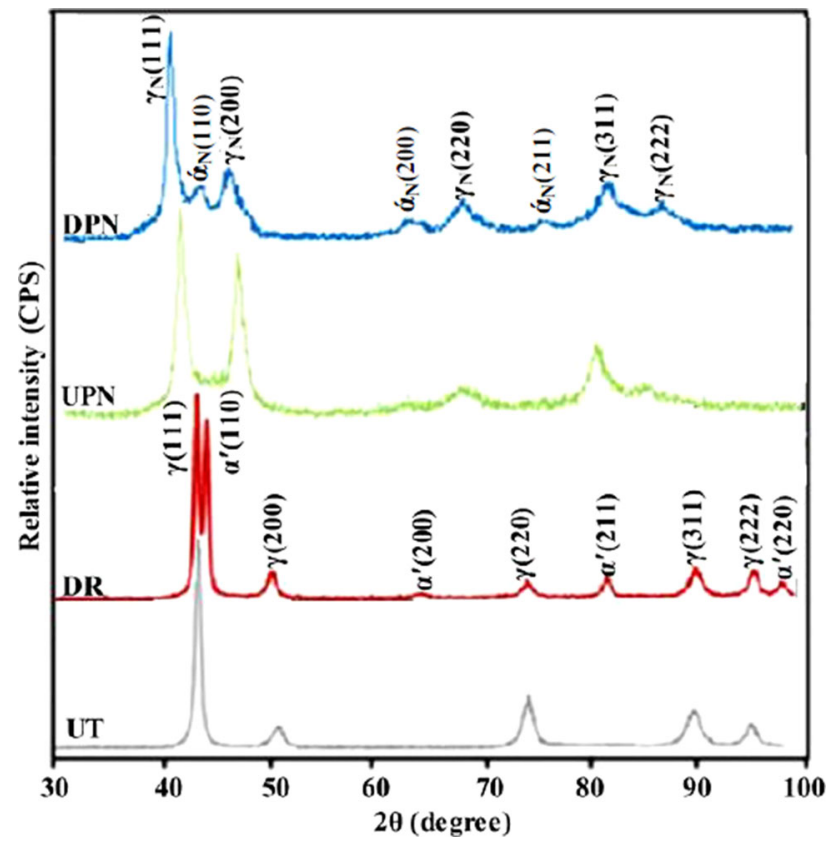

Fig. 3 X-ray diffraction patterns at different conditions; $U T$ asreceived, $D R$ deep rolled, $U P N$ untreated-plasma nitrided, $D P N$ deeprolled plasma nitrided

formation of a certain strain-induced martensite in austenitic stainless steels $[19,21]$. Thus, a change from austenitic phase to martensitic kind when applying deep rolling process is not a big surprise. While it is known that structure of austenitic stainless steels is significantly sensitive to plastic deformation $[24,25]$. Additional investigations with feritscope device also approve the formation of martensitic phase. The feritscope results revealed the formation of $8 \mathrm{Vol} . \% \alpha^{\prime}$ martensite after the deep rolling process. Thus, work hardening, grain refinement, and martensite formation are because of hardness increase in the deep-rolled surface layers. The martensitic transformation can be referred to the formation of intersecting mechanical twinnings near surface regions because of relatively low stacking fault energy of austenitic stainless steels $[19,21,25]$. The similar behavior has so far been reported in severe plastic deformation of such austenitic stainless steels by several mechanical surface treatments [17-20, 23]. By considering the mentioned structural changes, the density of rapid diffusional channels (crystalline defects) such as grain boundaries, twinning boundaries, and martensitic interfaces has been increased at deformed zones. Therefore, it is prospected that diffusivity of nitrogen in surface regions has been increased by the deep rolling process.

The SEM micrographs from the cross-section of the specimens after the plasma nitriding processes (UPN and DPN) have been shown in Fig. 4. Plasma nitriding at $450{ }^{\circ} \mathrm{C}$ has been led to the formation of expanded austenite
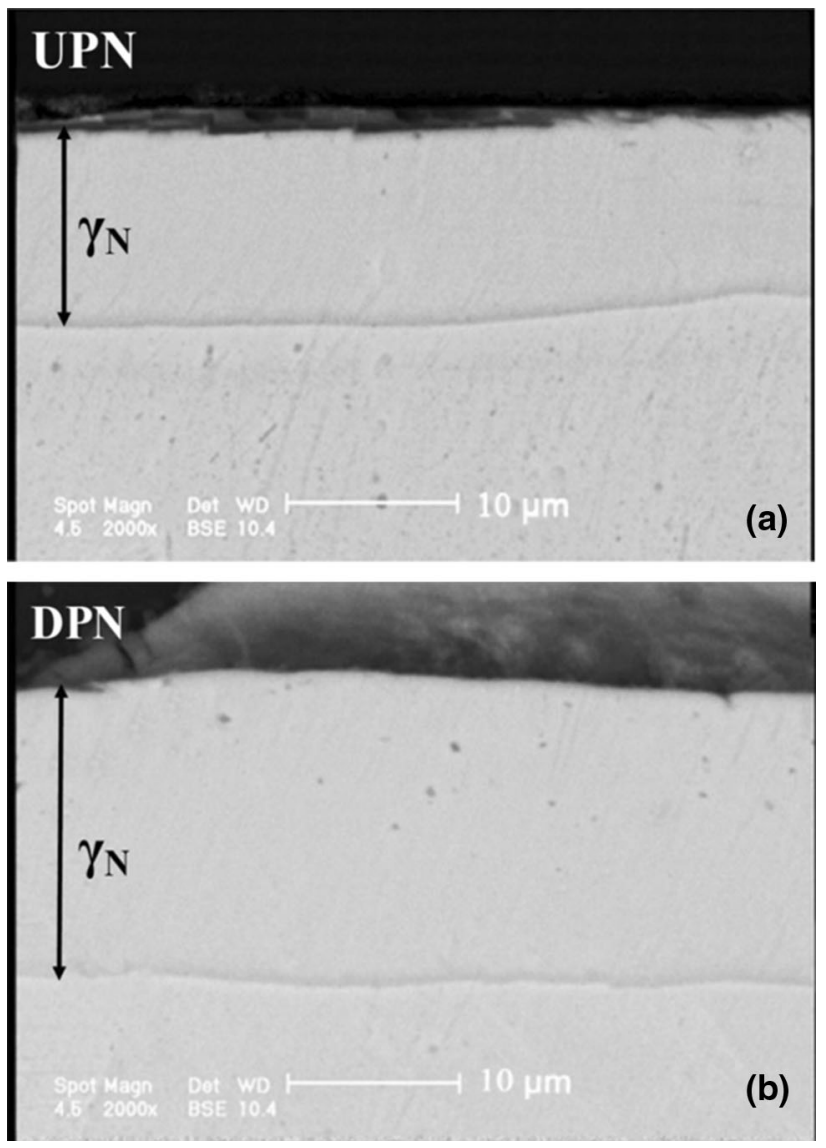

Fig. 4 The cross-section SEM micrograph after the a UPN and b DPN processes

" $\gamma_{\mathrm{N}}$ " in the UPN and DPN types as shown in the XRD spectrum (Fig. 3). The (111), (200), (220), (311), and (222) peaks of $\gamma_{\mathrm{N}}$ are seen in both the UPN and DPN patterns. These peaks have relatively equal $2 \theta$ position at both the processes, UPN and DPN. As seen in Fig. 4, the thickness of expanded austenitic layer in the UPN is about $12 \mu \mathrm{m}$, while in the DPN is about $20 \mu \mathrm{m}$. Increase in the thickness of nitrided layer can be attributed to the increase of crystalline defect density such as grain boundaries, mechanical twins, martensitic interfaces, and high-strained crystalline lattice, which are suitable paths for the rapid diffusion of nitrogen $[8,26,27]$. Therefore, conducting the deep rolling process prior to the nitriding can enhance the thickness of nitrided layer, due to the increase of nitrogen diffusion in surface layers. Similar tendency is seen in several previous works $[18,26]$, where, applying the mechanical surface treatments such as shot peening [18] and mechanical attrition [26] has been resulted in the increase of thickness of nitrided layer in the austenitic stainless steels.

Concentration depth profiles achieved from the GDOES measurements after the UPN and DPN processes are demonstrated in Figs. 5 and 6, respectively. As shown, the nitriding at $450{ }^{\circ} \mathrm{C}$ has been led to achieve a nitrogen-rich 
Fig. 5 GDOES concentration profiles of $\mathrm{Fe}, \mathrm{Cr}, \mathrm{N}$, and $\mathrm{Ni}$ elements near the surface layers after the UPN process
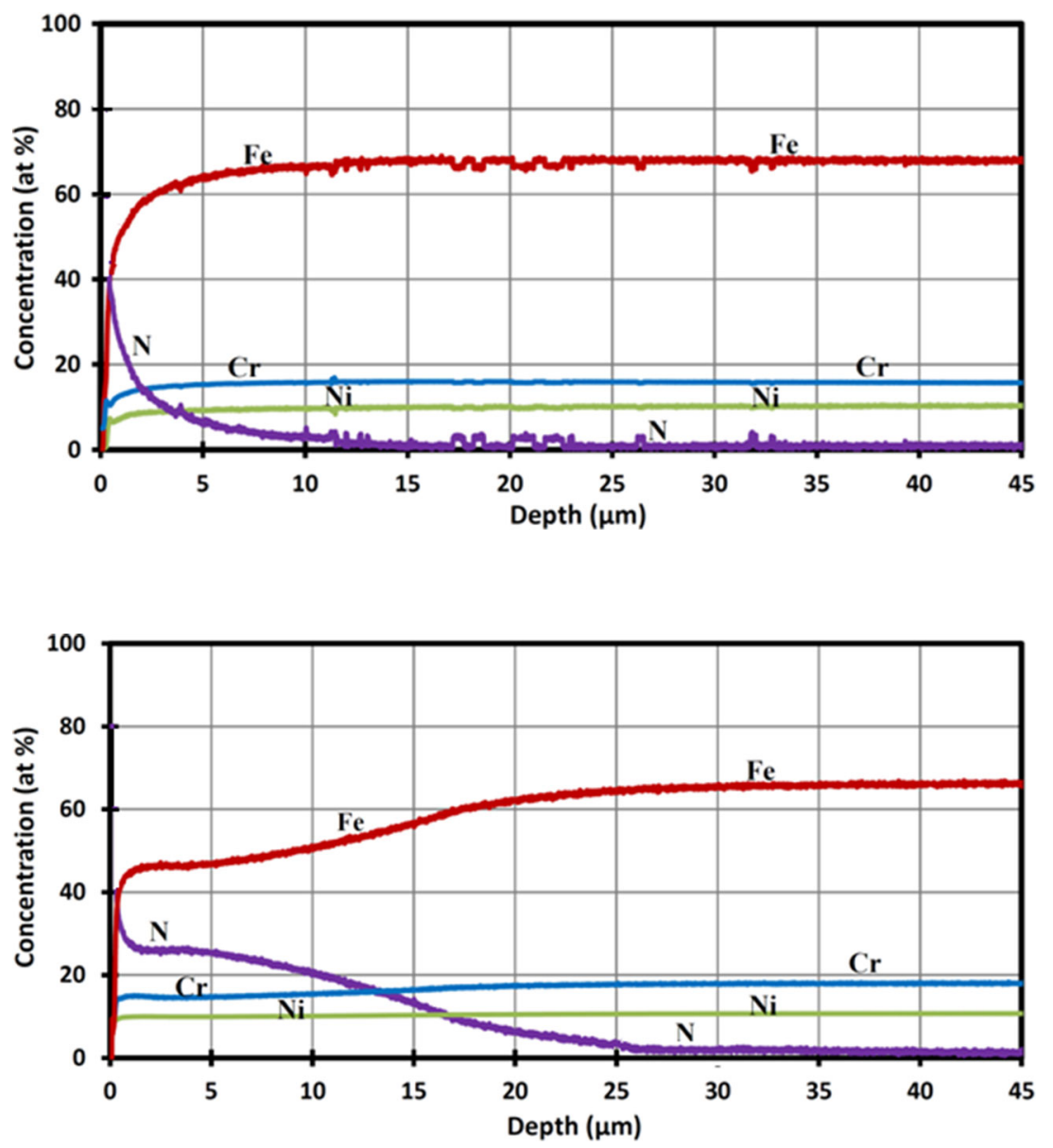

Fig. 6 GDOES concentration profiles of $\mathrm{Fe}, \mathrm{Cr}, \mathrm{N}$, and $\mathrm{Ni}$ elements near the surface layers after the DPN process zone in surface layers. Existence of high amounts of nitrogen at top-surface layer and afterwards its gradual reduction are observed in the surface regions of both the processes. The concentration increase of nitrogen at surface zones is a common feature between both the processes. While the atomic percent of $\mathrm{Fe}, \mathrm{Cr}$, and $\mathrm{Ni}$ elements are reduced with increase of nitrogen percent in near-surface zones. In contrast, no change in the elements present is found for both the processes at further depths, above 15 and $35 \mu \mathrm{m}$ for the UPN and DPN, respectively.

Three models have been suggested to illustrate the nitrogen diffusion in austenitic stainless steels [27]: (1) the trapping-detrapping model, (2) the concentration-dependent diffusion model based on Fick's laws and (3) the model combined of those two models. In the trappingdetrapping model, chromium atoms play a crucial role via a chemical bonding effect where $\mathrm{Cr}$ atoms form trap sites for $\mathrm{N}$ [28]. Hence, variation in $\mathrm{Cr}$ diffusion can be resulted in the change of nitrogen diffusion. According to studies, the simple diffusion has the main role on the nitrogen diffusion in the top-surface layer of the UPN sample where concentration of nitrogen is the highest. It is expected that effect of trapping-detrapping model can be increased at the further depths with lower concentration of nitrogen. While a nearly plateau-like appearance in concentration profile of nitrogen is not shown at further depths. It may be told due to the coarse grains of austenite phase in the UPN type (25 $\mu \mathrm{m})$, chromium atoms have a low diffusivity in surface zones. Hence, the effect of trapping-detrapping model is not high for the UPN, which resulted in the predominant role of the simple diffusion. Similar to the UPN, simple diffusion has the predominant role in the top-surface layer of the DPN with the highest nitrogen concentration, as shown in Fig. 6. The effect of trapping-detrapping is raised at the further depths of the DPN, containing the lower concentration of nitrogen unlike the UPN, resulting in the plateau-like appearance for the DPN profile. Due to the increase of crystalline defects density and formation of martensitic structure, substitutional diffusion of $\mathrm{Cr}$ in surface layers is increased. Hence, trapping-detrapping is the main mechanism for nitrogen diffusion at the DPN kind. While due to the lower diffusion of $\mathrm{Cr}$ in the UPN-inclusive lower rapid diffusional paths, the role of simple diffusion is higher.

The GDOES detectable profile of nitrogen concentration related to the UPN process has about $12 \mu \mathrm{m}$ average depth, 
equal to the thickness of the related $\gamma_{\mathrm{N}}$ layer illustrated in Fig. 4a. While GDOES detectable profile of nitrogen concentration has about $25 \mu \mathrm{m}$ depth for the DPN-treated kind as it is relatively near to the related $\gamma_{\mathrm{N}}$ layer with about $20 \mu \mathrm{m}$ thickness. However, diffusion depth of nitrogen after the DPN process is higher than the UPN one. Anomalous diffusion dependent on furthered crystalline defects, necessary increase of the nitrogen concentration as well as the filling of trapping sites before the starting of fast diffusion are understandable reasons for increase of nitrogen diffusion depth [29]. The FESEM micrograph after the DR process reveals a grain-refined structure corresponding to a high density of grain boundaries acceptable to increase of diffusion because of a defective atomic environment. On the other hand, the high diffusion depth of nitrogen can mainly be related to the grain boundary diffusion. Due to the low amount of induced martensite ( $8 \mathrm{Vol} \%)$, martensite has a low effect on the increase of nitrogen diffusion. According to studies, for bulk material with grain size more than $10 \mu \mathrm{m}$, the area fraction of these grain boundaries is negligible [29]. Thus, the nitrogen diffusion along them is below the detection limit. In contrast, grain boundaries are everywhere in nanocrystalline or amorphous materials, leading to the diffusion enhancement by a factor of 1000 [29]. This change is achieved by pre-mechanical working that induces a high density of rapid diffusional paths. Therefore, conducting deep rolling prior to nitriding can increase the nitrogen concentration and its diffusion depth will be result in the increase of nitrided layer thickness.

It is expected that the nitrided layer achieved by the DPN process has further hardness. This is due to the higher surface concentration of nitrogen, more thick nitrided layer, and near-surface work hardening resulted by the pre-deep rolling process. Surface hardness after the various processes is given in Fig. 7. As seen, surface hardness has been increased from 210 to $450 \mathrm{HV}_{0.1}$ after the DR process, indicating $240 \mathrm{HV}_{0.1}$ difference. While it has been increased up to $670 \mathrm{HV}_{0.1}$ after the UPN process, meaning $460 \mathrm{HV}_{0.1}$ hardness enhance. At the applied conditions, the raise of hardness through the plasma nitriding process is significantly further than the deep rolling one. In addition, conducting the deep rolling before nitriding characterised as the DPN process has noticeably been led to further surface hardness, about $1050 \mathrm{HV}_{0.1}$. Therefore, surface hardness of the steel has been increased about $840 \mathrm{HV}_{0.1}$, due to combination of the effects of the deep rolling and plasma nitriding. Increase in the surface concentration of nitrogen, formation of more thick nitrided layer, and near-surface work hardening achieved by pre-deep rolling are reasons for surface hardness enhancement. Considering further surface hardness after the DPN process compared with the

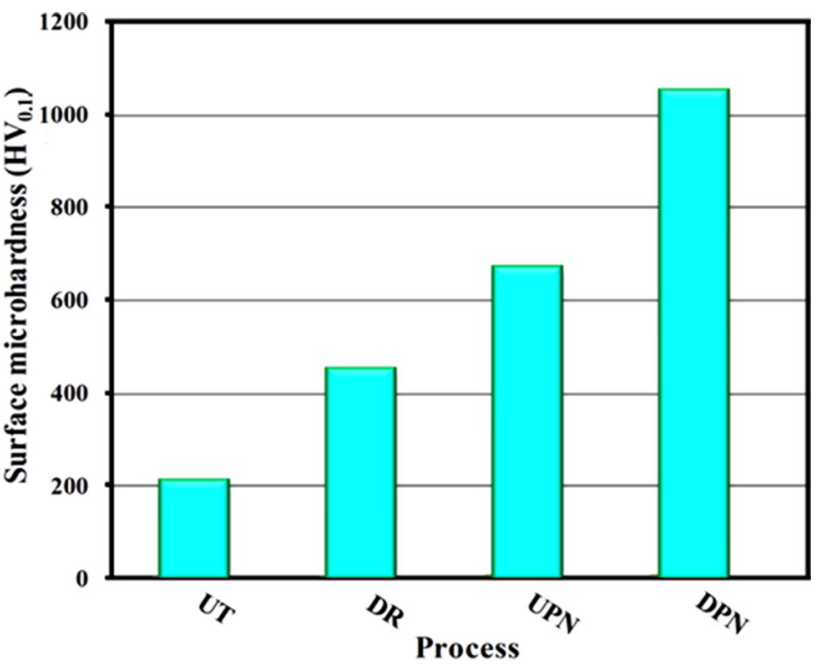

Fig. 7 Variation of surface hardness after the various processes; $U T$ as-received, $D R$ deep rolled, $U P N$ untreated-plasma nitrided, $D P N$ deep-rolled plasma nitrided

UPN may be told as nitrided layer in the DPN type has more hardness than that of the UPN. The similar behavior is seen in the previous works $[18,25,27]$, where conducting mechanical surface treatments such as shot peening or mechanical attrition before nitriding creates a thicker nitrided layer with further surface hardness in austenitic stainless steels.

\section{Conclusions}

- Applied deep rolling made an ultrafine austenitic structure and strain-induced martensitic transformation in the surface regions of the AISI 316L stainless steel.

- Plasma nitriding at the used conditions produced a hard-expanded austenitic layer at the steel surface.

- Surface hardness was increased from 210 up to 450 and $670 \mathrm{HV}_{0.1}$ after the deep rolling and plasma nitriding processes, respectively.

- Thickness and hardness of nitrided layer was enhanced through the pre-deep rolling.

- The highest surface hardness in about $1050 \mathrm{HV}_{0.1}$ was achieved in the deep-rolled plasma nitrided conditions.

- Diffusion depth and surface concentration of nitrogen were raised due to the further crystalline defects by the deep rolling process.

Open Access This article is distributed under the terms of the Creative Commons Attribution 4.0 International License (http://crea tivecommons.org/licenses/by/4.0/), which permits unrestricted use, distribution, and reproduction in any medium, provided you give appropriate credit to the original author(s) and the source, provide a link to the Creative Commons license, and indicate if changes were made. 


\section{References}

1. Lula, R.A.: Stainless Steel, 5th edn. American Society for Metals, Ohio (1985)

2. Harvey, P.D.: Engineering Properties of Steel, 4 th edn. American Society for Metals, Ohio (1982)

3. Lepienski, C.M., Nascimento, F.C., Foerster, C.E., Dasilva, S.L.R.: Glow discharge nitriding in AISI 304 at different nitrogen-hydrogen atmospheres: structural, mechanical and tribological properties. Mater. Sci. Eng. 489, 201-206 (2008)

4. Asgaria, M., Barnoush, A., Johnsena, R., Hoel, R.: Microstructural characterisation of pulsed plasma nitrided 316L stainless steel. Mater. Sci. Eng. 529, 425-434 (2011)

5. Menthe, E., Rie, K.-T.: Further investigation of the structure and properties of austenitic stainless steel after plasma nitriding. Surf. Coat. Tech. 116, 199-204 (1999)

6. Wang, J., Xiong, J., Peng, Q., Fan, H., Wang, Y.: Effects of DC plasma nitriding parameters on microstructure and properties of 304L stainless steel. Mater. Charact. 85, 38-47 (2009)

7. Lin, Y., Lu, J., Wang, L., Xu, T., Xue, Q.: Surface nanocrystallization by surface mechanical attrition treatment and its effect on structure and properties of plasma nitrided AISI 321 stainless steel. Act. Mater. 54, 5599-5605 (2006)

8. Mehrer, H.: Diffusion in Solids, 2nd edn. Springer, Berlin Heidelberg, New York (2007)

9. Liu, G., Lu, J., Lu, K.: Surface nanocrystallization of 316L stainless steel induced by ultrasonic shot peening. Mater. Sci. Eng. 286, 91-95 (2000)

10. Majzoobia, G.H., Azadikhah, K., Nematia, J.: The effects of deep rolling and shot peening on fretting fatigue resistance of Aluminum 7075-T6. Mater. Sci. Eng. 516, 235-247 (2009)

11. Zhang, H.W., Hei, Z.K., Liu, G., Lu, J., Lu, K.: Formation of nanostructured surface layer on AISI 304 stainless steel by means of surface mechanical attrition treatment. Act. Mater. 51, 1871-1881 (2003)

12. Arifvianto, B., Suyitno, M., Mahardika, P., Dewo, P.T., Iswanto, U.A.: Effect of surface mechanical attrition treatment (SMAT) on microhardness, surface roughness and wettability of AISI 316L. Mater. Chem. Phys. 125, 418-426 (2011)

13. Lu, J.Z., Zhang, L., Feng, A.X., Jiang, Y.F., Cheng, G.G.: Effects of laser shock processing on mechanical properties of $\mathrm{Fe}-\mathrm{Ni}$ alloy. Mater. Des. 30, 3673-3678 (2009)

14. Mordyuk, B.N., Milman, Y.V., Iefimov, M.O., Prokopenko, G.I., Silberschmidt, V.V., Danylenko, M.I., Kotko, A.V.: Characterization of ultrasonically peened and laser-shock peened surface layers of AISI 321 stainless steel. Surf. Coat. Tech. 202, 4875-4883 (2008)

15. Rao, M., Reddy, C.K., Rao, R.: The effect of roller burnishing on surface hardness and surface roughness on mild steel specimens. Int. J. Appl. Eng. Res. 7, 777-785 (2011)
16. Prabhu, P.R., Kulkarni, S.M., Sharma, S.S.: Influence of deep cold rolling and low plasticity burnishing on surface hardness and surface roughness of AISI 4140 steel. Eng. Tech. 72, 619-624 (2010)

17. Nikitin, I.: Altenberger, Comparison of the fatigue behavior and residual stress stability of laser-shock peened and deep rolled austenitic stainless steel AISI- 304 in the temperature range 25-600 ${ }^{\circ}$ C. Mater. Sci. Eng. 465, 176-182 (2007)

18. Hashemi, B., Rezaee Yazdi, M., Azar, V.: The wear and corrosion resistance of shot peened-nitrided $316 \mathrm{~L}$ austenitic stainless steel. Mater. Des. 32, 3287-3292 (2011)

19. Altenberger, I., Scholtes, B., Martin, U., Oettel, H.: Cyclic deformation and near surface microstructures of shot peened or deep rolled austenitic stainless steel AISI 304. Mater. Sci. Eng. 264, 1-16 (1999)

20. Ji, S.J., Wang, L., Sun, J.C., Hei, Z.K.: The effects of severe surface deformation on plasma nitriding of austenitic stainless steel. Surf. Coat. Tech. 195, 81-84 (2005)

21. Sun, Y.: Sliding wear behaviour of surface mechanical attrition treated AISI 304 stainless steel. Trib. Inter. 57, 67-75 (2013)

22. Tao, N.-R., Lu, J., Lu, K.: Surface nanocrystallization by surface mechanical attrition treatment. Mater. Sci. Forum 579, 91-108 (2008)

23. Altenberger, I.: Deep rolling - the past, the present and the future. Alter. Pro. 65, 144-155 (2005)

24. Lo, K.H., Shek, C.H., Lai, J.K.L.: Recent developments in stainless steels. Mater. Sci. Eng. 65, 39-104 (2009)

25. Eskandari, M., Najafizadeh, A., Kermanpur, A.: Effect of straininduced martensite on the formation of nanocrystalline $316 \mathrm{~L}$ stainless steel after cold rolling and annealing. Mater. Sci. Eng. A 519, 46-50 (2009)

26. Balusamy, T., Sankara Narayanan, T.S.N., Ravichandran, K., Park, I.S., Lee, M.H.: Plasma nitriding of AISI 304 stainless steel: role of surface mechanical attrition treatment. Surf. Coat. Tech. 212, 321-352 (2013)

27. Moskalioviene, T., Galdikas, A.: Stress induced and concentration dependent diffusion of nitrogen in plasma nitrided austenitic stainless steel. Vacuum 86, 1552-1557 (2012)

28. Moskalioviene, T., Galdikas, A., Rivière, J.P., Pichon, L.: Modeling of nitrogen penetration in polycrystalline AISI 316L austenitic stainless steel during plasma nitriding. Surf. Coat. Tech. 205, 3301-3306 (2011)

29. Manova, D., Höche, T., Mandl, S., Neumann, H.: Development of $\mathrm{CrN}$ precipitates during the initial stages of PIII nitriding of stainless steel thin films. Nucl. Instrum. Methods Phys. Res. 267, 1536-1539 (2009) 